Saudi Journal of Oral and Dental Research

Abbreviated Key Title: Saudi J Oral Dent Res

ISSN 2518-1300 (Print) |ISSN 2518-1297 (Online)

Scholars Middle East Publishers, Dubai, United Arab Emirates

Journal homepage: https://saudijournals.com/sjodr

\title{
Knowledge, Attitude and Perception on Clinical Implications of Behavior Management Techniques in UG Students: A Questionnaire Survey
}

\author{
Dr. Glorymol Raju ${ }^{1}$, Dr. Jyothi Krishnakumar, BDS ${ }^{2}$, Dr. Vijay Shekhar ${ }^{3 *}$, Dr. Faisal Noor Ahmad ${ }^{4}$, Dr. Rahul VC
} Tiwari OMFS, FOGS, PhD $^{5}$, Dr. Heena Tiwari BDS, PGDHHM ${ }^{6}$

\author{
${ }^{1}$ Dental surgeon, BDS, Bapuji Dental College and Hospital, Davangere, Karnataka India \\ ${ }^{2}$ Golden Hills, Vattapara Venkode, Trivandrum, Kerala India \\ ${ }^{3}$ Conservative Dentistry and Endodontics, Government Dental Surgeon, PHC Sampatchak, Patna, Bihar India \\ ${ }^{4}$ Postgraduate Student, Dept of Public Health Dentistry, Kothiwal Dental College and Research Center, Moradabad, Uttar Pradesh India \\ ${ }^{5}$ Dept of OMFS, Narsinbhai Patel Dental College and Hospital, Sankalchand Patel University, Visnagar, Gujarat India \\ ${ }^{6}$ Ex-Government Dental Surgeon, Chhattisgarh, India
}

DOI: $10.36348 /$ sjodr.2020.v05i07.008 $\quad$ | Received: 25.06.2020 | Accepted: 08.07.2020 | Published: 14.07 .2020

*Corresponding author: Dr. Vijay Shekhar

Abstract

Aim: The need for the present study was to assess the knowledge, attitude as well as perception of clinical implications of behavioral management techniques (BMT) in undergraduate students. Methodology: Our research enrolled 280 final year BDS students into the questionnaire survey. The survey consisted of 15 objective questions which were emailed to the survey participants. The questions were regarding the teaching of various behavior management techniques in the various institutes, and the attitude of the participants as to which method they are most likely to use according to the age group. Results: Our study showed that final year students had limited access to manage pediatric patients. Participants reported that one of the most common problems they faced in pediatric patients was to overcome their anxiety and fear of needles in the dental setup (75.3\%). Most common form of BMT which was observed by the UG students was 'Tell Show Do' technique (67.3\%), which made the pediatric patients familiar with dental set up. Conclusion: We observed that final year students need more exposure and better experience to handle pediatric patients with use of various behaviour management techniques, which will also help to build their confidence in accomplishing their professional goals later on.

Keywords Behavior management techniques, pediatric dentistry, undergraduate students.

Copyright @ 2020: This is an open-access article distributed under the terms of the Creative Commons Attribution license which permits unrestricted use, distribution, and reproduction in any medium for non-commercial use (NonCommercial, or CC-BY-NC) provided the original author and source are credited.

\section{INTRODUCTION}

One of the most challenging aspects of dental practice is working with the "difficult," challenging, or uncooperative patient. It is during these times that the dentist's clinical and patient management skills are most thoroughly tested. Success requires a personal knowledge of the patient and an understanding of human behavior, development, and cultural diversity. In the university clinic, students have the opportunity to learn, and put into practice, their first behavior management strategies. Thus, there are frequent opportunities for faculty to demonstrate behavioural techniques in a way that may potentially have a longterm impact on students and their practice. It is essential that these management techniques be useful and valid, as they will form the students' foundation for future patient interventions and outcomes [1]. Commonly, the pediatric patient provides the greatest challenge in behavior management. To guide dentists working with children, the American Academy of Pediatric Dentistry
(AAPD) has developed its Clinical Guidelines on Behavior Guidance for the Pediatric Dental Patient. The guidelines identify both basic and advanced behavior guidance techniques, as well as indications for their respective uses. These basic techniques, including communicative management, voice control, nonverbal communication, tell-show-do, positive reinforcement, distraction, parental presence/absence, and nitrous oxide/oxygen inhalation sedation, are indicated for all child patients and have few noted contraindications. Protective stabilization (formerly known as "medical immobilization"), sedation, and general anaesthesia were listed as advanced behavioural management techniques by the AAPD [2]. Their use is recommended only to those dentists who have completed commensurate advanced postdoctoral training (i.e., residency or continuing education) [6]. Psychological variables (anxiety and/or stress), sociocultural (individual characteristics, children's maturity, previous dental experience), and legal requirements (parent's 
Glorymol Raju et al; Saudi J Oral Dent Res, July, 2020; 5(7): 343-346

consent) are involved in dental treatment interfering with professional performance [4]. To be successful in pediatric dental treatment, it is necessary to choose adequate strategies based on procedures that stimulate children's cooperative behavior and knowledge which should have been acquired during formal dentistry training [5]. Apart from these techniques, behavioural management strategies start as soon as the patient arrives in the dental operatory, and also involve attire, voice tone, facial expression, body language, sense of humour of the dentist. For a child who is not capable of cooperate, the dentist has to rely on other behavior management techniques (BMTs) as communication and education [6]. A wide range of procedures has been used to manage children's behavior. Tell-show-do (TSD) was introduced in 1959 and it is one of the most frequently used techniques. It involves the explanation of what is going to happen, in appropriate way to child's comprehension, then the demonstration and finally, the procedure is performed. In the Voice control, volume and tone of voice are changed to achieve the child's attention during a disruptive behavior. Eufemisms are also widely used and consists in metaphors and comparisons to facilitate child's understanding (i.e. 'your teeth are going to sleep'). Distraction is another well-established strategy in pediatric dentistry, which includes the presentation of cartoons, videos, music, stories or even talks to the patients to deflect their attention away during the treatment. When is used to keep instruments potentially harmful out of the patient's view, for example, during the local anaesthetic injection, it is defined as Blunting [7]. In the Positive Verbal Reinforcement, children are praised when show acts of cooperation. When they receive something of value, like toys or sticker-badges as a reward for being cooperative; it is named promising a toy [8]. Modelling was described as the process of acquiring behavior through observation of a model, who may be parents, teachers, siblings or any other child, since she/he has good behavior during the treatment [9]. Some restrictive methods are also used, like Active Immobilization by dentist and/or dental assistants [10]; Passive Immobilization, when mechanical device or equipment are used to restricts child's movement [11] and Hand-over-mouth exercise (HOME), that consists in placing the hand gently over the child's mouth, in cases of hysterical behavior, and explains calmly what the behavioural expectations. Although dental schools provide opportunities to build clinical and behavioural management skills, they also serve to shape students' attitudes towards those skills. Researchers are just beginning to empirically examine behavioural management training within dental schools, and limited attention has been paid to the role of students in this training [12].

\section{AIM OF THE STUDY}

The need for the present study was to assess the knowledge, attitude as well as perception of clinical implications of behavioral management techniques in undergraduate students.

\section{METHODOLOGY}

Our research enrolled 280 final year BDS students into the questionnaire survey. Survey questions (Table 1) were emailed to the survey participants. Final year students were selected because they had recently completed the behavioural sciences course in pediatric dentistry and had begun direct patient care. Furthermore, the selection of these students provided an opportunity to evaluate their exposure to, and their use of behavioural management techniques in novice clinicians, with only one year or less of clinical practice. The questions were regarding the teaching of various behavior management techniques in the various institutes, and the attitude of the participants as to which method they are most likely to use according to the age group. The students were also asked to note any additional techniques which they might be using in clinical practice, besides the ones mentioned in the questionnaire. Their responses were recorded on a Microsoft Excel spreadsheet and were subjected to descriptive statistical analysis to assess their responses to the questionnaire.

\section{RESULTS}

It was observed in our study that final year students had limited access to manage pediatric patients, where number of patients handled by these UG students varied from 10-40, with an average of 23 patients. Most common age group that visited the pediatric clinics was of 6-10 years of age (56\%). Participants reported that one of the most common problem they faced in pediatric patients was to overcome their anxiety and fear of needles in the dental setup $(75.3 \%)$, followed by discomfort of drilling sound of handpiece $(45.1 \%)$ as well as extremely uncooperative patients who were afraid of being in the presence of a dentist (15.6\%). (Table 2) Most common form of BMT which was observed by the UG students was 'Tell Show Do' technique (67.3\%), which made the pediatric patients familiar with dental set up. This technique was also best for patients in the age group of 6-10 years of age $(86 \%)$. In case of patients with age group of 3-6 years, positive reinforcement as well as their parent's involvement helped more (56.9\%). In case of very young pediatric patients, mostly parents were actively involved, explained the procedure as well as they were asked to sit in dental chair with their ward (87\%). However, patients who were older than 10 years, desensitization technique were helpful $(81.7 \%)$. Conscious sedation was preferred in overtly uncooperative patients $(73.4 \%)$. However, sedation with nitrous oxide and anesthesia for medically challenged children was overwhelming for the UG students (96\%). In $69.4 \%$ younger patients, audio-visual aids helped to educate them about the procedures in pediatric dental clinic as well as oral hygiene measures. According to 
final year students, oral health check-up camps helped to increase the awareness of proper dental care in case of pediatric patients $(97 \%)$.

Table-1: Questionnaire used in the present study

\begin{tabular}{|l|l|}
\hline S.No. & Questions \\
\hline 1 & What is the prominent age group of patients usually you come across in pediatric clinic? \\
\hline 2 & How many pediatric patients you have managed? \\
\hline 3 & Most common problems that is faced with pediatric patients? \\
\hline 4 & What is the most commonly observed BMT in the clinic? \\
\hline 5 & $\begin{array}{l}\text { According to age group of pediatric patients, which BMT can be helpful to manage them in a dental } \\
\text { clinic? }\end{array}$ \\
\hline 6 & For overtly uncooperative patients, what kind of management technique is preferred? \\
\hline 7 & $\begin{array}{l}\text { Which is the most difficult BMT technique to apply in dental clinic for pediatric patients, according } \\
\text { to your experience? }\end{array}$ \\
\hline 8 & $\begin{array}{l}\text { How do you educate the pediatric patients or their parents (in case of younger patients) regarding } \\
\text { dental procedures? (oral/audio/visual aids) }\end{array}$ \\
\hline 9 & How can you increase awareness for oral health in pediatric patients on a larger setting? \\
\hline
\end{tabular}

Table-2: Data recorded in the present questionnaire survey

\begin{tabular}{|l|l|}
\hline Questions & Data observed \\
\hline Prominent age group of patients in pediatric clinic & 6-10 yrs of age (56\%) \\
\hline Pediatric patients managed & $10-40$ patients (Average 23 patients) \\
\hline $\begin{array}{l}\text { Most common problems that is faced with pediatric } \\
\text { patients }\end{array}$ & $\begin{array}{l}\text { - Anxiety and fear of needles in the dental setup (75.3\%) } \\
\text { - Discomfort of drilling sound of handpiece }(45.1 \%)\end{array}$ \\
\hline Most commonly observed BMT & 'Tell Show Do' technique (67.3\%) \\
\hline BMT according to age group of pediatric patients & $\begin{array}{l}\text { 0-3 years- parents active involvement and restraint } \\
3-6 \text { years- Positive reinforcement }\end{array}$ \\
\hline BMT in overtly uncooperative patients & $\begin{array}{l}\text { 6-10 years- Tell show do } \\
10 \text { years and above- Desensitization }\end{array}$ \\
\hline Most difficult BMT technique to apply & Conscious sedation (73.4\%) \\
\hline Best way to educate the pediatric patients & $\begin{array}{l}\text { Conscious sedation with nitrous oxide and general } \\
\text { anesthesia (96\%) }\end{array}$ \\
\hline $\begin{array}{l}\text { Best way to increase awareness for oral health in } \\
\text { pediatric patients }\end{array}$ & Audio-visual aids (69.4\%) \\
\hline
\end{tabular}

\section{DISCUSSION}

While dental school training also seems to accurately reflect real-world dental practice, the effectiveness of specific training in behavioural management skills is unclear. Previous investigations have used a variety of methods to examine dental school teaching practices. Instructors, patients, and students themselves have all provided valuable information regarding the effectiveness of dental education. To estimate the concordance between their attitudes towards difficult patients, predoctoral dental students and their instructors were given hypothetical patient scenarios and asked to rate the difficulty of the interaction. In addition to finding an agreement that "difficult patients" were those who were "aggressive" and "manipulative," these researchers found that the most effective teaching method for learning to manage the difficult patient was simply observation of the skills in clinical practice. However, these students were then rated for competency by the same instructors they observed; thus, those students likely to be considered "competent" were those who behaved most like their instructors, regardless of the efficacy of their interventions [13]. The acceptance of paediatric dental behaviour guidance techniques is influenced by clinical experience. When students experience more exposure of clinical environment and training, as a consequence, they are more capable in choosing the suitable behaviour management for each patient. This is evidenced by increasing acceptability of behaviour guidance educational techniques (tell-show-do, positive reinforcement), cognitive behaviour guidance techniques (distraction), competitive stimuli (taking advantage of the child's imagination, distraction with music or video), rewards and graded exposure (modelling).The low acceptability are found for coercion or aversive techniques (HOM and not allowing the child to speak), which reflect the fact that students were thought not to use this technique since it might cause uncomfortable to both parents and child, as well as it has been eliminated from the American Association of Pediatric Dentistry clinical guidelines in 2006 [14]. The observation would serve just to shape 
students' attitudes, because to develop skills of stimulate children's cooperative behavior and to have effective interventions, it is also necessary the daily practice. Only when they put in practice a certain technique to manage their own patients, students may be able to evaluate the results and judge if that technique is effective and/or acceptable, basing their practices on evidences. Another study also suggested that there is a correlation between the type of training received and the practitioners' level of comfort/ frequency using the techniques [15]. These findings justify the efforts that dental schools should make to improve student's learning. It was concluded that undergraduate dental education components have the potential to shape student perceptions of pediatric dental behavior management techniques during their career, because of this; professors should take into consideration the potentially significant effects of undergraduate dental education on students' perceptions of behavior management techniques.

\section{CONCLUSION}

We observed that final year students need more exposure and much more experience to handle pediatric patients with use of behaviour management techniques. The didactic and clinical educational components of paediatric dental behaviour management may bring a huge influence and potential in shaping their student perceptions about it in their career.

\section{REFERENCES}

1. York, K. M., Mlinac, M. E., Deibler, M. W., Creed, T. A., \& Ganem, I. (2007). Pediatric behavior management techniques: a survey of predoctoral dental students. Journal of dental education, 71(4), 532-539.

2. American Academy of Pediatric Dentistry. Clinical guidelines on behavior guidance for the pediatric dental patient.

At: www.aapd.org/media/policies.asp.

3. Ng, M. W. (2004). Behavior management conference panel IV report-Educational issues. Pediatric Dentistry, 26(2), 180-183.

4. Klaassen, M. A., Veerkamp, J. S. J., \& Hoogstraten, J. (2007). Dental fear, communication, and behavioural management problems in children referred for dental problems. International Journal of Paediatric Dentistry, 17(6), 469-477.

5. Batista, C. G., Nascimento, C. L., Rolim, G. S., Rocha, R. A. S. S., Rodrigues, A. F., Ambrosano,
G. M. B., \& Moraes, A. B. A. (2011). Student self- confidence in coping with uncooperative behaviours in paediatric dentistry. European Journal of Dental Education, 15(4), 199-204.

6. Freeman, R. (1999). The case for mother in the surgery. British dental journal, 186(12), 610-613.

7. De Oliveira, R. V. D., Ângelo, A. C. B., de Araujo Brito, D. B., de Medeiros, R. C. G., Forte, F. D. S., \& Sousa, S. A. (2015). Student's Perceptions about Pediatric Dental Behavior Guidance Techniques throughout a five-year Dental Curriculum. Pesquisa Brasileira em Odontopediatria e Clínica Integrada, 15(1).

8. Roberts, J. F., Curzon, M. E. J., Koch, G., \& Martens, L. C. (2010). behaviour management techniques in paediatric dentistry. European Archives of Paediatric Dentistry, 11(4), 166-174.

9. Farhat-McHayleh, N., Harfouche, A., \& Souaid, P. (2009). Techniques for managing behaviour in pediatric dentistry: comparative study of live modelling and tell-show-do based on children's heart rates during treatment. Journal of the Canadian Dental Association, 75(4).

10. Kantaputra, P. N., Chiewcharnvalijkit, M. S. K., Wairatpanich, K., Malikaew, P., \& Aramrattana, A. (2007). Children's attitudes toward behavior management techniques used by dentists. Journal of Dentistry for Children, 74(1).

11. Wilson, S. (2013). Management of child patient behavior: quality of care, fear and anxiety, and the child patient. Pediatric dentistry, 35(2), 170-174.

12. Newton, J. T., Naidu, R., \& Sturmey, P. (2003). The acceptability of the use of sedation in the management of dental anxiety in children: views of dental students. European Journal of Dental Education, 7(2), 72-76.

13. Seoane, J., Varela- Centelles, P., Guimaraes, J., García- Pola, M. J., González- Reforma, N., \& Walsh, T. F. (2002). Concordance between undergraduate dental students and their lecturers in their attitudes towards difficult patients. European Journal of Dental Education, 6(4), 141-146.

14. Mohd Ali, N., \& Hamzah, S. H. (2018). Dental Students' Perceptions on Behaviours Management for children.

15. Juntgen, L. M., Sanders, B. J., Walker, L. A., Jones, J. E., Weddell, J. A., Tomlin, A. M., ... \& Maupome, G. (2013). Factors influencing behavior guidance: a survey of practicing pediatric dentists. Pediatric dentistry, 35(7), 539-545. 